\title{
Social Work in the Department of Defense Hospital: Impact of the Work
}

\author{
Joan C. Beder
}

\begin{abstract}
Social workers in the Department of Defense Hospital system are faced with numerous challenges to best address the needs of the war wounded. Social workers serve diverse roles on the multidisciplinary team and are integral to the hospital and hospital out-patient work environment. Sometimes, however, the work extracts a toll on the social worker that may be expressed in terms of burnout and compassion fatigue. The converse is also true, that social workers may have a strong sense of compassion satisfaction about what they do. This article details the experience of social workers in Department of Defense hospitals. It describes the impact of the work on the social workers noting levels of compassion satisfaction, compassion fatigue, and burnout.
\end{abstract}

Keywords: Military social workers, compassion satisfaction, compassion fatigue, burnout

\section{INTRODUCTION}

Quantitative research is the systematic investigation of phenomena that can be analyzed numerically. Quantitative research is often done using surveys, structured questionnaires and/or multiple-choice questions. Results are often presented as 'hard numbers' using varied statistical techniques for analysis (Patten, 2004). The quantitative research reported in this article sought to inform the social service/military community about the experience of social workers working in the Department of Defense health care system, specifically evaluating levels of compassion satisfaction, compassion fatigue and burnout.

The care of our wounded service members is divided into two systems - the Department of Defense and the Veterans Administration. While there is some overlap in terms of care, the usual trajectory for service members who have been wounded is that they will return to the United States and begin their treatment in a Department of Defense hospital. Some of the less seriously injured - physically and/or emotionally - are treated and will return to active duty overseas; for the more seriously wounded, those who will not be able to return to active duty, their medical situation is stabilized and ultimately their care is transitioned to a Veterans Administration (VA) facility, ideally near their home and family.

The Department of Defense employs approximately 500 social workers placed in 26 treatment facilities (hospitals offering both in- and out-patient care), within 6 regions across the United States. The DoD social workers may be military or civilian. Within each DoD facility social workers, as part of the multidisciplinary medical team, are managing caseloads of patients with complex psychosocial, mental and physical health needs. According to Robichaux and Keesee (2008) the responsibility of the multidisciplinary team within the DoD is to ensure delivery of optimal health care while eliminating barriers, restrictions, and the stigma associated with injury, illness and

Joan Beder, DSW, is professor at the Wurzweiler School of Social Work at Yeshiva University in New York City. The author would like to acknowledge the support of the U.S. Army Medical Department and the U.S. Army Medical Command in this research project and particularly the gracious support of the Medical Command's Health Policy and Services Directorate, Behavioral Health Division. 
disability. This allows the service member to focus on both physical and psychological healing and to enable a return to good health.

Despite the integral role for social workers, limited research exists detailing the impact of their work experience - specifically, levels of compassion satisfaction, compassion fatigue and burnout - for the social workers. Within the DoD system, many social workers are working with OIF/OEF service members with severe injuries, PTSD and Traumatic Brain Injury. Caseloads have increased as so many soldiers are surviving their injuries. Chivers (2011) reported “...that fewer than 7.9 percent of the Americans wounded in 2010 died, down from more than 11 percent the previous year and 14.3 percent in 2008. The reasons for the decline in death rates are mainly due to enhanced levels of care for the wounded, body armor and heavier armored vehicles. What this 'improvement' implies for the DoD and VA systems of care is a large and continuing influx of seriously wounded service members with intense and substantial physical and psychosocial needs” (p. 1).

The study described in this article sought to examine whether a caseload, dominated by OIF/OEF service members cared for in a DoD facility, had an impact on the social worker in terms of compassion fatigue, burnout and compassion satisfaction. Were there particular units within the hospital that were more stressful (measured by burnout and compassion fatigue) for the social worker, regardless of their immersion in OIF/OEF? What was the impact on $\mathrm{CF}, \mathrm{BO}$ and $\mathrm{CF}$ of a number of variables? It was anticipated that findings on this study would be helpful for social work administrators within the DoD and by extension, the VA system.

\section{PURPOSE}

The war in Afghanistan is nearing the tenth year and the Iraq War has entered its eighth year. Yet, there remains a paucity of research on clinicians who deliver health and mental health care to the returning troops. These clinicians - physicians, social workers, nurses - are faced with the daunting challenge of providing clinical treatment to a complex cohort amidst the collective shared trauma of ongoing war (Tyson, 2007). While there has been a great deal of research on post traumatic stress disorder among trauma survivors, few researchers have examined the effects that traumatic events (such as war injury) have on people who are indirectly exposed to traumatic content, specifically, the helpers (Palm, Polusny, \& Follette, 2004). More recently, as noted by BallengerBrowning, Schmitz, Rothacker, Hammer, Webb-Murphy, and Johnson (2010), “...little is known about the burden of treating mental health disorders in the military” (p. 253).

Social workers play a vital role in the multidisciplinary team within the DoD health care system and may be involved with mental health treatment, staff consultation, offering support for caregivers and family members, and participation in utilization review (Rahia, 1999) as well as primary responsibility for direct patient interaction, support and care. In these diverse roles, the social worker is in daily contact with those severely injured and/or those who may have experienced traumatic injury to their body or mind. Family members are also part of the caseload and often require as much if not more care and attention that the injured service member. In almost all cases, the patient, 
family and the social worker can anticipate difficulties with readjustment to the service member's injury, potential for redeployment and/or adjustment to civilian life. The social worker is expected to be responsive to and involved in helping make that transition while involving caretakers and family members in the care of the patient.

While engaged in their work, the social worker faces many challenges: helping the patient, engaging the family, managing increasing workloads and bureaucratic expectations. All of this is done in the context of being as supportive as possible to the needs of the service members and his/her family and within the context of a social work relationship based on empathy and caring. In the course of doing their work, social workers are exposed to the experiences of the returning service member as they recount what happened to them during the war. Figley (1995) comments that "There is a cost to caring. Professionals (social workers) who listen to clients' stories of fear, pain, and suffering may feel similar fear, pain, and suffering because they care...The professional's work, centered on the relief of the emotional suffering of clients, automatically includes absorbing information that is about suffering. Often it includes absorbing that suffering as well” (p. 17). This absorption can lead the helper to a variety of responses.

\section{Compassion Satisfaction, Compassion Fatigue and Burnout}

Three major constructs help describe the potential for impact on social workers that work mainly with service members: compassion satisfaction (CS), compassion fatigue (CF) and burnout (BO). Each construct addresses an aspect of the possible response of a social worker to their work. While CF, CS and BO are not limited to social workers in the military, this study details only the military cohort.

\section{Compassion Satisfaction}

Compassion satisfaction relates to the pleasure derived from being able to do your work well. It includes feelings regarding satisfaction with one's ability to be a caregiver, one's feelings toward their colleagues, and their ability to make a contribution in the lives of another (Stamm, 2005). “ To flourish, social workers experience the joy of helping others and find satisfaction in their work. This joy and satisfaction can lead to compassion satisfaction, including a sense of fulfillment derived from seeing clients suffer less and watching them transform from the role of victim to survivor (Radey \& Figley, 2007, p. 208). Many in the helping professions experience compassion satisfaction and have a positive feeling while doing work that is sustaining and nourishing (Bride, Radey, \& Figley, 2007). Often, however, compassion satisfaction can be compromised by feelings of compassion fatigue.

\section{Compassion Fatigue}

Compassion fatigue - aka secondary traumatic stress and vicarious traumatization refers to the negative effects on the clinician due to work with the traumatized client, effects that leave the clinician depleted to some degree and unable to adequately or more fully engage empathically with the client (Bride, 2007; Adams, Boscarino, \& Figley, 2006). At some point in the life of most professionals, there will be a period of time when 
compassion fatigue occurs. This is not unique to social workers. However, the likelihood of experiencing compassion fatigue is higher for those who work with the traumatized (Gentry, Baranowsky, \& Dunning, 2002). Research has documented that the following groups have reported compassion fatigue: first responders (Salston, 2002), child protection workers (Bride, Radey, \& Figley, 2007; Myers \& Cornille, 2002; NelsonGardell \& Harris, 2003); mental health counselors (Brady, Guy, Poelstra, \& FletcherBrokaw, 1999; Pearlman \& Mac Ian, 1995); domestic violence counselors (Bell, 2003); sexual assault counselors (Ghahramanlou \& Brodbeck, 2000; Schauben \& Frazier, 1995); NY City social workers who worked with clients after the 9/11 attack on the World Trade Center (Boscarino, Figley, \& Adams, 2004); substance abuse counselors (Bride, 2007) and, various other healthcare services (Cunningham, 2003; Dane \& Chachkes, 2001). This expanse of research supports the assertion that caregivers of the traumatized are at risk for experiencing symptoms of compassion fatigue/traumatic stress, disrupted cognitive schema, and general psychological distress as a result of their work (Bride, Robinson, Yegisdis, \& Figley, 2004). By extension, those who work with those traumatized by war are also at high risk for development of compassion fatigue.

For those who experience compassion fatigue, there is greater potential for disruption in the helper's experience of safety, trust, power, esteem, intimacy, independence, and control (McCann \& Pearlman, 1990; Pearlman \& Saakvitne, 1995). Additional symptoms of anxiety, disconnection, avoidance of social contact, difficulty in maintaining the therapeutic alliance, depression, somatization and disrupted beliefs about the self and others are also identified as possible outcomes of compassion fatigue (Cunningham, 2003; Pearlman \& Saakvitne, 1995).

\section{Burnout}

Burnout “...is associated with feeling of hopelessness and difficulties in dealing with work or in doing your job effectively. These negative feelings usually have a gradual onset. They can reflect the feeling that your efforts make no difference, or they can be associated with a very high workload or a non-supportive work environment" (Stamm, 2005, p. 8). Symptoms of burnout include feeling strained by having to work with people, issues with concentration and attention level and decreasing memory of work related details (National Center for PTSD, 2004). Burnout is often associated with bureaucratic demands that the worker feels are difficult to address or amend. Empirical studies of burnout reveal it as an especially prevalent condition among helping professionals with mental health professionals demonstrating higher levels of burnout than primary healthcare workers (Sprang, Clark, \& Whitt-Woosley, 2007). Burnout differs from compassion fatigue in that compassion fatigue is the direct result of hearing emotionally shocking material from clients; burnout is a problem of the social environment in which people work. Issues such as workload, lack of control and input into the system, insufficient rewards, unfairness, etc. are all potential causes of burnout (Canfield, 2005).

Burnout is conceptualized as a defensive response to prolonged occupational exposure to demanding interpersonal situations that produce psychological strain and provide inadequate support (Jenkins \& Baird, 2002, p. 424.) The process of 'burning out'

is described as a “...progressive state occurring cumulatively over time with contributing 
factors related to both the individual, the populations served, and the organization...." (Newell \& MacNeil, 2010, p. 59). Maslach, Jackson, and Leiter's (1996) view of burnout - a widely acknowledged perspective - is that it can be conceptualized as a multidimensional construct with three distinct domains: emotional exhaustion, depersonalization, and reduced sense of accomplishment. Other attributes of burnout include physical exhaustion, dissatisfaction about oneself, cynicism towards clients (Ballenger-Browning, et al., 2011).

In a recent study (Ballenger-Browning, et al., 2011) comparing levels of burnout among mental health providers serving the military and a normative sample of mental health providers serving a civilian population, it was noted that burnout in military mental health providers was similar to that reported in similar studies of mental health workers. Of particular value in the study were the findings that patient caseload (both size and type), long working hours, amount of clinical experience, gender, occupation, and social support at work were predictors of burnout in the mental health providers working with the military.

\section{METHODS}

\section{Instrumentation}

The Professional Quality of Life Scale is a 30-item self-report measure that assesses the potential for Compassion Satisfaction (CS), the risk of Compassion Fatigue (CF) and risk of Burnout (BO). According to the creators of the scale, it is "...the most commonly used measure of the positive and negative effects of working with people who have experienced extremely stressful events" (Stamm, 2010, p. 12). The scale has been translated into numerous languages. The scale is available on the ProQoL website and "may be freely copied as long as (a) the author is credited, (b )no changes are made and (c) it is not sold except for in agreement specifically with the author" (Stamm, 2010, p. 5).

The scale is easily administered and takes about 7-10 minutes to complete. Respondents are instructed to indicate how frequently each item was experienced in the last 30 days. Each item is anchored in a 6-item Likert scale (o=never, 1=rarely...5-very often). Scoring requires summing the item responses for each 10 -item subscale. Five scores are reversed, $(1,4,15,17$ and 29) before computing total subscale scores (Stamm, 2010).

The alpha reliabilities of the scale are: Compassion Satisfaction $=.87$, Compassion Fatigue $=.80$ and Burnout $=.72$. The scale has good construct validity and is well validated with over 200 articles noted in the peer review literature (Stamm, 2005). Higher scores on the Compassion Satisfaction (CS) subscale indicate the subject is experiencing better satisfaction with his/her ability to provide care (e.g., care giving is an energy enhancing experience, increased self-efficacy). Higher scores on the Compassion Fatigue (CF) subscale indicate the subject is at higher risk for compassion fatigue. Higher scores on the Burnout (BO) subscale indicate the subject is at risk of experiencing symptoms of burnout (e.g., hopelessness, helplessness, and depression). 
The average score on the compassion subscale is 37 (SD 7; alpha scale reliability .87). About $25 \%$ of people score higher than 42 and about $25 \%$ score lower than 33 . If you are in the higher range, you probably derive a good deal of professional satisfaction from your position. If you score lower than 33, you may be having proems with your job. The average score on the compassion fatigue scale is 13 (SD 6, alpha scale reliability .80). About $25 \%$ of people score higher than 17 and about $25 \%$ score lower than 8 . If one score is above 17, you may want to take some time to understand and address your fears and work at what is frightening to you. On the burnout subscale, the average score is 22 (SD 6.0, alpha scale reliability.72) About 25\% of people score higher than 27 and about $25 \%$ score lower than 18 . If your score is below 18, this reflects positive feelings about your ability to be effective in your work. If your score is above 22, you may wish to think about what it is at work that makes you feel like you are not effective in your work (Stamm, 2005).

Caution in interpreting the scores is suggested in that the scale is not designed as a diagnostic tool but is more designed to 'raise flags' and be a guide to both subjects and administrators as areas of concern and attention (Stamm, 2010, p. 18).

\section{Recruitment Procedure}

This study was initiated at a large DoD hospital in the northeast United States. Institutional Review Board permission was granted to do both face-to-face and Survey Monkey interviews and an email soliciting participation in the study was sent to several DoD hospitals through the initial IRB granting institution. Survey Monkey is an Internet computer program that allows a researcher to place their survey on a site that the subject can access through a dedicated link. Responses were blinded so the researcher did not know where the responses were coming from and as no identifying information was noted on the survey, full anonymity was guaranteed. In both cases - Survey Monkey or face-to-face interviewing - the social worker guaranteed confidentiality and anonymity for both person and venue. Several face-to-face interviews were conducted to help refine the survey before sending it out system wide. The sample was considered a convenience sample comprised of those who agreed to participate; it was clearly stated that participation by the social worker was voluntary.

The survey consisted of essential demographic information (see Figure 1) and the ProQoL instrument which measures compassion satisfaction, compassion fatigue and burnout. It was anticipated that the responder would spend about fifteen minutes completing the survey. All data from the surveys was aggregated. 
Figure 1. DoD Interview Questions

\section{Basic demographics}

Age: 25-35 35-45 45-55 $55-65$ $65+$

Gender: $\mathrm{M}$ F

How long have you been working as a MSW? 0-5 years $6-10$ 11-15_15+

How long have you worked in the DoD system? 0-5 years 6-10 11-15 $15+$

How long have you worked with OIF/OEF Veterans? 0-5 years 6-10

What service do you work on? Surgical PTSD TBI Behavioral Health Other Case Mgmt. Administration

Do you work In-pt or Out-pt

\section{Sample}

One hundred forty-one social workers from 26 treatment facility venues completed surveys. Table 1 shows the demographics of the study sample. As can be seen, the subjects were mostly female (75\%), mainly working in out-patient services, with over $50 \%$ with less than 5 years within the DoD hospital system. In addition, $80 \%$ had been working with the OEF/OIF population for 5 years or less, with a majority of social workers (37\%) working in Behavioral Health.

\section{RESULTS}

In general, the sample ( $\mathrm{n}=141)$ was above the reported national norms on the ProQoL sub-scales (Stamm, 2005). While the compassion satisfaction mean score was 39.22 with a range from 23 to 50; 59\%of the sample was higher than the nationally normed score of 37. The mean score for compassion fatigue was 21.5 with a range from 12 to 33; $45 \%$ of the sample was higher than the nationally normed score of 17 . The burnout mean score was 28.22 with a range from $10-38$ with $66.2 \%$ above the national norm of 22 . To simplify this finding, this sample of social workers registered positive feelings (compassion satisfaction) about their work with over 59\% feeling strongly positive. The scores on the compassion fatigue scale were high indicating the presence of compassion fatigue with $45 \%$ of the sample registering levels of compassion fatigue. In the area of burnout, the social workers were strongly above the norm with $66.2 \%$ registering high levels of burnout. 
Table 1. Demographic Characteristics of Study Participants $(\mathrm{N}=141)$

\begin{tabular}{|c|c|c|c|}
\hline Characteristic & & $\mathbf{N}$ & $\%$ \\
\hline \multirow{5}{*}{ Age: } & $25-35$ & 10 & 07.1 \\
\hline & $36-45$ & 32 & 22,7 \\
\hline & $46-55$ & 50 & 35.5 \\
\hline & $56-65$ & 42 & 29.8 \\
\hline & $>65$ & 7 & 05.0 \\
\hline \multirow[t]{2}{*}{ Gender: } & Male & 37 & 25.5 \\
\hline & Female & 104 & 74.5 \\
\hline \multirow[t]{6}{*}{ Years as an MSW: } & $0-5$ & 10 & 07.1 \\
\hline & $6-10$ & 27 & 19.1 \\
\hline & $11-15$ & 34 & 24.1 \\
\hline & $16-20$ & 19 & 13.5 \\
\hline & $21-25$ & 16 & 11.3 \\
\hline & $>25$ & 35 & 24.8 \\
\hline \multirow{5}{*}{ Years in the DOD: } & $0-5$ & 82 & 58.2 \\
\hline & $6-10$ & 25 & 17.7 \\
\hline & $11-15$ & 17 & 12.1 \\
\hline & $16-20$ & 9 & 06.4 \\
\hline & $>20$ & 8 & 05.6 \\
\hline \multirow[t]{2}{*}{ Years working with OEF/OIF: } & $0-5$ & 112 & 79.4 \\
\hline & $6-10$ & 29 & 20.6 \\
\hline \multirow[t]{2}{*}{ Inpatient/ Outpatient: } & Inpatient & 17 & 12.1 \\
\hline & Outpatient & 124 & 27.9 \\
\hline \multirow[t]{7}{*}{ Service: } & Surgical & 10 & 07.1 \\
\hline & PTSD & 39 & 27.7 \\
\hline & TBI & 9 & 06.4 \\
\hline & Behavioral Health & 52 & 36.9 \\
\hline & Case Mgmt. & 6 & 04.3 \\
\hline & Administration & 15 & 10.6 \\
\hline & Other (FAP etc.) & 10 & 07.1 \\
\hline
\end{tabular}

An independent samples t-test was conducted to compare the levels of CS, CF and BO for those who work $50 \%$ and those who work $75 \%$ of their time with OEF/OIF service members. For those workers who spent $50 \%$ of their time with OEF/OIF service members, the scores on the subscales were minimally different, registering statistical significance ( $\left.\mathrm{p}^{>} .05\right)$ only on CS, i.e., those social workers who worked $50 \%$ of their time with OEF/OIF service members experienced higher levels of CS. For those social workers who spent $75 \%$ of their time with OEF/OIF, the difference in the scores on the subscales was not statistically significant. 


\section{Table 2. Demographic Findings on ProQoL (N=141)}

Compassion Satisfaction (CS) - national norm $=37$

Compassion Fatigue $(\mathrm{CF})$ - national norm $=17$

Burnout $(\mathrm{BO})-$ national norm $=22$

\begin{tabular}{|c|c|c|c|c|c|}
\hline Characteristic & & $\mathbf{n}$ & CS & CF & BO \\
\hline \multirow[t]{5}{*}{ Age: } & $25-35$ & 10 & 36.90 & 21.40 & 26.00 \\
\hline & $36-45$ & 32 & 38.94 & 22.15 & 28.38 \\
\hline & $46-55$ & 50 & 39.12 & 22.17 & 28.25 \\
\hline & $56-65$ & 42 & 39.88 & 20.86 & 28.62 \\
\hline & $>65$ & 7 & 40.57 & 18.00 & 28.00 \\
\hline \multirow[t]{2}{*}{ Gender: } & Male & 37 & 38.81 & 21.68 & 28.30 \\
\hline & Female & 104 & 39.37 & 21.45 & 28.19 \\
\hline \multirow[t]{6}{*}{ Years as an MSW: } & $0-5$ & 10 & 39.00 & 19.20 & 28.70 \\
\hline & $6-10$ & 27 & 37.96 & 23.43 & 27.89 \\
\hline & $11-15$ & 34 & 40.18 & 21.03 & 27.56 \\
\hline & $16-20$ & 19 & 40.21 & 32.21 & 28.89 \\
\hline & $21-25$ & 16 & 38.50 & 19.94 & 27.81 \\
\hline & $>25$ & 35 & 39.15 & 20.88 & 28.82 \\
\hline \multirow[t]{6}{*}{ Years in the DOD: } & $0-5$ & 82 & 38.66 & 22.21 & 28.70 \\
\hline & $6-10$ & 25 & 40.16 & 21.44 & 26.12 \\
\hline & $11-15$ & 17 & 39.88 & 20.17 & 29.06 \\
\hline & $16-20$ & 9 & 39.56 & 19.33 & 28.33 \\
\hline & $21-25$ & 4 & 43.00 & 18.00 & 29.25 \\
\hline & $>25$ & 4 & 37.50 & 19.50 & 26.75 \\
\hline \multirow{2}{*}{ Years working with OEF/OIF: } & $0-5$ & 112 & 39.18 & 21.68 & 28.04 \\
\hline & $6-10$ & 29 & 39.39 & 20.82 & 28.96 \\
\hline \multirow{2}{*}{ Inpatient/ Outpatient: } & Inpatient & 17 & 40.94 & 18.88 & 27.24 \\
\hline & Outpatient & 124 & 38.98 & 21.87 & 28.30 \\
\hline \multirow[t]{7}{*}{ Service: } & Surgical & 10 & 42.40 & 20.80 & 27.40 \\
\hline & PTSD & 39 & 39.85 & 22.59 & 28.69 \\
\hline & TBI & 9 & 36.00 & 20.33 & 30.44 \\
\hline & Behavioral Health & 52 & 38.33 & 21.96 & 28.71 \\
\hline & Case Mgmt. & 6 & 40.50 & 16.83 & 24.00 \\
\hline & Administration & 15 & 38.80 & 20.40 & 26.33 \\
\hline & Other (FAP etc.) & 10 & 40.94 & 21.20 & 28.00 \\
\hline
\end{tabular}




\section{ProQoL Differences by Demographics}

Multiple regression is a statistical technique used to examine the effect of multiple variables on a dependent variable. This technique allows the researcher to identify which factors, from a group of factors, predict an outcome; in this case, which factors create the findings on the ProQoL subscales.

Multiple regression was conducted to determine which variables (age, gender, years in the DoD, years as a social worker, and years working with OEF/OIF) were predictors of CS, CF and BO. Regression results for CS indicated that no variable was reliable in predicting CS. For CF, the only variable that was a reliable predictor was years working in the DoD health care system with higher CF scores for those working in the system from 0-5 years with CF decreasing over time. For BO, no variables were predictive.

\section{ProQoL by Service}

Social workers were asked to identify which service they worked on (Surgical, PTSD, TBI, Behavioral Health, Case Management, Administration). Scores on the CS, $\mathrm{CF}$ and $\mathrm{BO}$ subscales were studied to assess scores by service worked. For CS, the three highest scores for the social workers were on the Surgical service, followed by Case Management and Administration - i.e., these three services registered the highest levels of compassion satisfaction, in that order. Those social workers working with PTSD, followed by Behavioral Health and Surgical recorded the highest scores on CF. The social workers working with TBI followed by Behavioral Health and PTSD recorded the highest scores on BO. It is important to note that the differences in these scores was not dramatic, perhaps a few points, but noteworthy nonetheless.

The ProQoL subscales also evaluated the social workers to determine the impact of in-patient versus out-patient work. Survey responders were asked to indicate whether the majority of their work was with in-patients or out-patients. Scores on the subscales for CS and BO were not statistically significant based on in- or out-patient service however the score on the CF scale registered statistical significance $(\mathrm{p}=>.05)$, i, e., those social workers who had a caseload that was predominately out-patient had higher levels of compassion fatigue.

Multiple regression was conducted to determine which variables - service, years in the DoD health care system and whether the social worker worked in- or out-patient predicted subscale scores (See Table 3). None of the three variables was a predictor for $\mathrm{CS}$; for CF, each variable was predictive in the following order - whether the social worker was in- or out-patient, years in the DoD system and service worked; for BO, the only predictor was service worked with those working with traumatic brain injuries scoring the highest levels. 
Table 3. Results of Multiple Regression Analysis - Predictors of Compassion Satisfaction

\begin{tabular}{lrrrrr}
\hline Factor & B & Std. Error & Beta & t & Sig. \\
\hline Age & 2.055 & .655 & .169 & 1.611 & .109 \\
MSW (yrs) & -.485 & .559 & -.126 & -.868 & .387 \\
DoD (yrs) & .482 & .533 & .098 & .903 & .368 \\
OEF/OIF (yrs) & -.496 & 1.581 & -.031 & -.314 & .754 \\
Gender & .328 & 1.291 & .023 & .254 & .800 \\
Service & -.022 & .281 & -.007 & -.080 & .937 \\
In-pt/Out-pt & -2.302 & 1.738 & -.119 & -1.325 & .187 \\
\hline${ }^{*} \mathrm{p}<0.05 * * \mathrm{p}<0.01$ & & & & & \\
\hline
\end{tabular}

Table 4. Results of Multiple Regression Analysis - Predictors of Compassion Fatigue

\begin{tabular}{lcrrrl}
\hline Factor & B & Std. Error & Beta & t & Sig. \\
\hline Age & -.874 & .475 & -.183 & -1.842 & .068 \\
MSW (yrs) & .699 & .405 & .237 & 1.727 & .087 \\
DoD (yrs) & -.895 & .387 & -.237 & -2.313 & $.022^{*}$ \\
OEF/OIF (yrs) & .594 & 1.146 & .049 & .518 & .605 \\
Gender & -.235 & .936 & -.021 & -.252 & .802 \\
Service & -.427 & .204 & -.175 & -2.091 & $.038^{*}$ \\
In-pt/Out-pt & 3.738 & 1.260 & .252 & 2.967 & $.004^{* *}$ \\
\hline${ }^{*} \mathrm{p}<0.05 * * \mathrm{p}<0.01$ & & & & & \\
\hline
\end{tabular}

Table 5. Results of Multiple Regression Analysis - Predictors of Burnout

\begin{tabular}{llrrrl}
\hline Factor & B & Std. Error & Beta & \multicolumn{1}{c}{ T } & Sig. \\
\hline Age & .194 & .470 & .043 & .412 & .681 \\
MSW (yrs) & .373 & .401 & .133 & .929 & .354 \\
DoD (yrs) & -.468 & .383 & -.130 & -1.221 & .224 \\
OEF/OIF (yrs) & 1.433 & 1.135 & .124 & 1.263 & .209 \\
Gender & -.033 & .927 & -.003 & -.035 & .972 \\
Service & -.474 & .202 & -.204 & -2.345 & $.021^{*}$ \\
In-pt/Out-pt & 1.552 & 1.248 & .110 & 1.244 & .216 \\
\hline${ }^{*} \mathrm{p}<0.05 * * \mathrm{p}<0.01$ & & & & & \\
\hline
\end{tabular}

Findings - Recap for this sample of social workers:

- $\quad$ CS, CF and BO all registered above the subscale normed means;

- For those social workers who worked 50\% of their time with OEF/OIF, CS was high; for those who work $75 \%$ of their time no subscale scores were elevated; 
- In evaluating demographic factors, BO and CS subscales were not related to demographic factors; CF was noted in those who were with the DoD system 0-5 years;

- For those who worked on the Surgical, Case Mgmt. and Administration, higher levels of CS were noted, for those who work with PTSD, Behavioral Health and Surgical, higher levels of CF were noted; for those who work with TBI, Behavioral Health and PTSD, higher levels of BO were noted;

- For those who work with out-patients, higher levels of CF were noted, not so with CS and BO;

- In evaluating the impact of service, years with the DoD and in-patient factors, none were related to CS, out-patient, years with the DoD (0-5 years in the system) and service were related to CF and only service was related to BO.

\section{DISCUSSION}

This sample of social workers represents approximately $35 \%$ of the total social work staff in the DoD (141 sample of 500 social workers in the system). As such, the findings assume a fairly strong level of credibility as reflective of the feelings of the social workers system-wide.

Generally the social workers expressed compassion satisfaction derived from their work with 59\% above national norms for the subscale. Of some concern were the findings on the compassion fatigue and burnout subscales. While almost every social worker at some point will feel fatigued and burned out, over half of the responders (59\%) noted levels of fatigue and two-thirds (66.2\%) noted levels of burnout. This finding is not necessarily reflective of the OEF/OIF influx as scores on the subscales were not higher when social workers worked either $50 \%$ or $75 \%$ of their time with this specific cohort of returning service members. In fact, just the opposite; a surprising finding was that for those social workers who worked $50 \%$ of their time, their levels for compassion satisfaction were significantly (statistically) higher than those whose caseload was under $50 \%$. The elevated CF and BO subscale scores suggests that attention to the burnout and compassion fatigue symptoms of the social workers might be initiated. These scores can be seen as reflecting the need for investigation of setting characteristics that might influence the development of these conditions.

To further refine the $\mathrm{CF}$ and $\mathrm{BO}$ findings, the analysis indicated that the service areas where the high CF and BO scores occurred were those working with PTSD, Behavioral Health, Surgery and TBI. These might be areas where administration could focus intervention designed to ease some of the pressure on these units.

Another area of concern, which was indicated in the analysis of the subscales, was the CF and BO scores for those social workers new to the system. Both subscale scores were statistically significant - above normed levels - for those in the system $0-5$ years. As the years went on, in five-year increments, the subscale scores went down to below CF and BO normed levels. This suggests that there is a 'settling in' process, an acculturation into the system and to the work that leads to diminished levels of CF and BO. To smooth 
the transition into the system, administration might consider particular attention to the new worker who may be assailed with challenges not anticipated when joining the system.

The in-patient/out-patient finding - that those working in an out-patient setting had higher scores on the CF subscale - might be reflective of the location and size of the facilities in which the social workers are placed. On in-patient services, the interdisciplinary atmosphere and larger pool of workers might buffer some of the feelings of compassion fatigue. This finding might well be further researched to determine what specific action could address these responses. Perhaps diversifying case assignments might be helpful with time spent working both in- and out-patients.

\section{LIMITATIONS}

Interpretation of the findings of this study is limited by several factors. First, the design of the study utilized and relied on one instrument for its research. As noted earlier, the instrument is not to be considered diagnostic but more trend based; as such it is possible that the participant taking the survey might be having a 'bad day' or a few bad days which would be reflected in the responses on the ProQoL. In addition, as a selfreport device, many may have chosen not to respond to the call for participation, noting time constraints and other work obligations.

\section{CONCLUSION}

"In many ways, the health of an organization depends on the health of its staff. This is especially important for industries like health care.....These facilities are often challenged when providers are worn down by either their work environment (burnout) or the content of their work (compassion fatigue)" (Rudolph, Stamm, \& Stamm, 1997, p. 88). Since social workers are an integral component of the multidisciplinary team in the DoD systems such, their care and well-being is important to the overall quality of care offered to our service members.

The research reported in this article can be seen as a snapshot, a picture in time, which reflects a certain reality. As with any snapshot, the picture can change. As the war efforts in Iraq and Afghanistan continue and our wounded service members continue to return home, the work in the Department of Defense Health Care System will not ease, if anything, it will become more intense. Work demands will increase. The social workers in the system are dedicated professionals working on behalf of our wounded. For the most part, as reflected in this study, they derive a large degree of satisfaction from their work. Due to the nature of the work and the degree of caring, there is the potential for experiencing compassion fatigue and burnout. For optimal care to be given to our wounded, attention to staff needs is warranted. The findings in this article - not to be seen as a critique - point to certain areas in the social work experience that merit attention.

On-going research on the experience of social workers is needed to help social work administrators to be sensitive to the needs of their staffs, especially as caseloads expand and the war effort continues. 


\section{References}

Adams, R., Boscarino, J., \& Figley, C. (2006). Compassion fatigue and psychological distress among social workers: A validation study. American Journal of Orthopsychiatry, 76(1), 103-08.

Ballenger-Browning K. K., Schmitz, K. J., Rothaker, J., Hammer, P. S., Webb-Murphy, J. A., \& Johnson, D. C. (2011). Predictors of burnout among military mental health providers. Military Medicine, 176, 253-260.

Bell, H. (2003). Strengths and secondary trauma in family violence work. Social Work, 48, 513-522.

Boscarino, J., Figley, C. R., \& Adams, R. E. (2004). Compassion fatigue following the September 11 terrorist attacks: A study of secondary trauma among New York City social workers. International Journal of Emergency Mental Health, 2, 1-10.

Brady, J. L., Guy, J. D., Poelstra, P. L., \& Fletcher-Brokaw, B. (1999). Vicarious traumatization, spirituality, and the treatment of sexual abuse survivors: A National survey of women psychotherapists. Professional Psychology, Research and Practice, 30, 386-393.

Bride, B. (2007). Prevalence of secondary traumatic stress among social workers. Social Work, 52, 63-70.

Bride, B., Radey, M., \& Figley, C. R. (2007). Measuring compassion fatigue. Journal of Clinical Social Work, 35, 155-63.

Bride, B., Robinson, M. M., Yegidis, B. L., \& Figley, C. R. (2004). Prevalence of secondary traumatic stress among social workers. Social Work, 52(1), 63-70.

Canfield, J. (2005). Secondary traumatization, burnout, and vicarious traumatization: A review of the literature as it relates to therapists who treat trauma. Smith College Studies in Social Work, 75(2), 81-102.

Chivers, C. J. (2011, January 8). In wider war, more survive their wounds. NY Times, p. A7.

Cunningham, M. (2003). Impact of trauma work on social work clinicians. Social Work, 48(4), 451-59.

Dane, B., \& Chachkes, E. (2001) .The cost of caring for patients with an illness: Contagion to the social worker. Social Work in Health Care 33(2), 31-51

Figley, C. R. (1995). Compassion fatigue: Coping with secondary traumatic stress disorder in those who treat the traumatized. London: Routledge.

Gentry, J. E., Baranowsky, A., \& Dunning, K. (2002). The accelerated recovery program for compassion fatigue. In C. R. Figley (Ed.), Treating compassion fatigue (pp. 7593). NewYork: Brunner Mazel. 
Ghahramanlou, M. A., \& Brodbeck, C. (2000). Predictors of in sexual assault trauma counselors. International Journal of Emergency Mental Health , 2, 229-240.

Jenkins, S. R., \& Baird, S. (2002) Secondary traumatic stress and vicarious trauma: A validation study. Journal of Traumatic Stress, 15(5), 423- 432.

Maslach, C., Jackson, S. E., \& Leiter, M. P. (1996). Maslach Burnout Inventory Manual, Ed. 3. Mountain View, Ca: CCP, Inc.

McCann, I. L., \& Pearlman, L. A. (1990). Vicarious traumatization: A framework for understanding the psychological effects of working with victims. Journal of Traumatic Stress, 3, 131-149.

Meyers, T. W., \& Cornille, T.A. (2002). The trauma of working with traumatized children. In C. R. Figley (Ed.), Treating compassion fatigue (pp. 39-55). New York: Brunner-Mazel.

National Center for PTSD. (2004). Iraq war clinician guide. Washington, DC: Dept. of Veterans Affairs.

Nelson-Gardell, D., \& Harris, D. Childhood abuse history, secondary traumatic stress, and child welfare workers. Child Welfare, 82, 5-26.

Newell, J., \& MacNeil, G. (2010). Professional burnout, vicarious trauma, secondary traumatic stress and compassion fatigue. Best Practices in Mental Health, 6(2), 57-68

Palm, K., Polusny, M., Follette, V. (2004). Vicarious traumatization: Potential hazards and interventions for disaster and trauma workers. Prehospital and DisasterMedicine, 19(1): 73-78.

Patten, M. L. (2004). Understanding research methods: An overview of the essentials $\left(4^{\text {th }}\right.$ ed.). Glendale, DA: Pyrczak.

Pearlman, L. A., \& Mac Ian, P. S. (1995). Vicarious traumatization: An empirical study of the effects of trauma work on trauma therapists. Professional Psychology: Research and Practice, 26(6), 558-565.

Pearlman, L. A., \& Saakvitne, K. (1995). Trauma and the therapist. New York: W.W. Norton.

Radey, M., \& Figley, C. (2007). The social psychology of compassion. Clinical sSocial Work Journal, 35, 207-214.

Rahia, N. (1999). Medical social work in the US armed forces. In J. G. Daley (Ed.), Social work practice in the military (pp. 107-121). New York: Haworth Press.

Robichaux, R., \& Keesee, N. (2008). What can social workers do for warriors in transition? US Army Med Dept J, 25-26.

Rudolph, M. A., Stamm, B. H., \& Stamm, H. E. (1997, November). Compassion fatigue: A concern for mental health policy, providers and administration. Poster presented at the $13^{\text {th }}$ annual conference of the International Society for Traumatic Stress Studies, Montreal, CAN. 
Salston, M. D. (2000). Secondary trauma: Implications for mental health professionals and trainees. Unplublished cldoctoral dissertation, Florida State University.

Schauben, L. J., \& Frazier, P. (1995). Vicarious trauma: The effects on female counselors of working with sexual violence survivors. Psychology of Women Quarterly, 19(1), 49-64.

Sprang, G., Clark, J., \& Whitt-Woosley, A. (2007). Compassion fatigue, compassion satisfaction and burnout. Journal of Loss and Trauma, 12, 259-279.

Stamm, B. H. (2005). The ProQOL Manual. The professional quality of life scale: Compassion satisfaction, burnout \& compassion fatigue/secondary trauma scales. Baltimore, MD: Sidran.

Stamm, B. H. (2010). The concise manual for the professional quality of life scale $\left(2^{\text {nd }}\right.$ ed.). Pocatello, ID: ProQoL.org.

Tyson, J. (2007). Compassion fatigue in the treatment of combat related trauma during wartime. Journal of Clinical Social Work, 35, 183-92.

\section{Author's note:}

Address correspondence to: Professor Joan Beder, Wurzweiler School of Social Work at Yeshiva University, 500 W. 185th St, New York, NY 10033. E-mail: beder@yu.edu 


\section{Appendix 1}

\section{PROFESSIONAL QUALITY OF LIFE SCALE}

Helping others puts you in direct contact with other people's lives. As you probably have experienced, your compassion for those you help has both positive and negative aspects. Consider each of the following questions about you and your current situation. Write in the number that honestly reflects how frequently you experienced these characteristics in the last 30 days.

0=Never 1=Rarely 2=A Few Times 3=Somewhat Often 4=Often 5=Very Often

1. I am happy.

2. I am preoccupied with more than one person I help.

3. I get satisfaction from being able to help people.

4. I feel supported by the staff I work with.

5. I jump or am startled by unexpected sounds.

6. I feel invigorated after working with those I help.

7. I find it difficult to separate my personal life from my life as a helper.

8. I am losing sleep over a person I helped traumatic experiences.

9. I think that I might have been infected by the traumatic stress of those I help.

10. I feel trapped by my work as a helper.

11. Because of my helping, I feel "on edge" about various things.

12. I like my work as a helper.

13. I feel depressed as a result of my work as a helper.

14. I feel as though I am experiencing the trauma of someone I have helped.

15. I have beliefs that sustain me.

16. I am pleased with how I am able to keep up with helping techniques and protocols.

17. I am the person I always wanted to be.

18. My work makes me feel satisfied.

19. Because of my work as a helper, I feel exhausted.

20. I have happy thoughts and feelings about those I help and how I could help them.

21. I feel overwhelmed by the amount of work or the size of the caseload I have to deal with.

22. I believe I can make a difference through my work.

23. I avoid certain activities or situations because they remind me of frightening experiences of the people I help.

24. I plan to be a helper for a long time.

25. As a result of my helping, I have intrusive, frightening thoughts.

26. I feel "bogged down" by the system.

27. I believe that I am a "success" as a helper.

28. I can't recall important parts of my work with trauma victims.

29. I am an unduly sensitive person.

30. I am happy that I chose to do this work.

(C) B. Hudnall Stamm, 2003. Professional Quality of Life: Compassion Fatigue and Satisfaction Subscales, RIII. The authors of the scale have given permission for free copying of the scale as long as the items are not changed, the authors are credited, and the scale is not sold. 